\title{
Analysis on the Effective Application of Micro Blog in Normal School Students' Teaching Practice
}

\author{
Baohai Yang ${ }^{1, a^{*}}$, Dong Chen ${ }^{1, b}$, Rixin $\mathrm{Hu}^{1, \mathrm{c}}$ and Qin $\mathrm{Xu}^{1, \mathrm{~d}}$ \\ ${ }^{1}$ College of Electronic Engineering, Jiujiang University, Jiujiang, 332005, China \\ ayangbaohai@sohu.com, bdchen1@163.com, crxhu@126.com, ${ }^{\mathrm{d}} 23029773 @ q q . c o m$ \\ ${ }^{*}$ The Corresponding author
}

Keywords: Normal school students'; Micro blog; Teaching practice; Effective application strategies

\begin{abstract}
With the continuous reform and advancement of education, requirements for teachers' professionalism are more and more strict. Normal students are generally engaged in education and teaching in the future, and the teaching practice ability will directly influence their future performance in teaching position. Abundant practice knowledge is closely linked with the future teaching level. And the effective application of micro blog can bring great advantage to their teaching practice. This paper analyzes the situation of practical teaching in normal school students and the advantage of effectively using micro blog teaching practice, and puts forward some effective application strategies of micro blog in teaching practice of the normal students.
\end{abstract}

\section{Introduction}

The premise for teaching position is the engagement of some abilities of teaching, management and self-development. Normal students are the main sources of the future teacher. Therefore, in order to lay a solid foundation for the future teaching position, it is necessary to vigorously educate and develop the normal students' abilities of teaching, management and self development. The practice ability has a significant value for the normal students. In recent years, colleges and universities have taken some measures to improve and strengthen the students' teaching practice ability, but there still exist some problems: teacher education and student practice cannot be achieved simultaneously, and the lack of communication between the students and their instructors during the practice, thus the instructors may not know the students in time and so on. Therefore, some teaching methods are needed to assist the normal students' teaching practice, and micro blog is an effective teaching assistant, which can help normal students quickly understand the practice environment and the content of their work, can also strengthen the communication between instructors and students. Therefore, there exist great significance and value in actively exploring the application of micro blog.

\section{Present Situation and Problems in Teaching Practice of the Normal Students}

Teaching is a highly professional occupation. It needs not only the professional knowledge of education, but also a wealth of teaching practice experience. In order to have professional performance, the normal colleges and universities are continuously enriching their students practice with a wide range of teaching practice activities to improve the students practice ability. Although the institutions are always taking various forms of teaching practice, there still exist some problems in their teaching of practice.

Lack of Teaching Instruction. Most of the practice activities of the normal colleges and universities are instructed by the teachers in their faculties to provide professional instruction to students. Due to the lack of concentration in time and places of the practice activities, his activities of the practice groups will certainly be inconsistent. Therefore, in the course of practice, it is difficult for the students to frequently assemble and communicate with the instructors. The lack of communication with the instructors leads to shortage of professional instructions. And instructors cannot master and manage the actual practice of students timely and effectively. 
Limitation of Practice Time. The time for teaching practice activities is generally limited in normal colleges and universities. For example, the arrangement of education practice is generally 6 to 8 weeks including the time for familiarizing the environment, leaving students short time for education practice.

Narrow Practice Activities. Most of the normal institutions organize their practice activities according to locations, practice environment and ways of practice. During their practice, there is the shortage of chance in communication. They may only know their practice contents and conditions. In the management of the practice classroom, it is necessary to make the students know the other practice base and the other practice contents.

Inaccurate Evaluation Results. The decentralized characteristics of the time and place of the practice make the instructors unable to observe and understand the practice timely, which results in inaccurate evaluation of the students practice activities. Meanwhile, the practice score is usually given by the instructors in the practice place, which may be a little random.

\section{Advantage of Effective Application of Micro Blog in Normal Students' Teaching Practice}

Micro blog is a way to allow users to timely update and publish the short text. It is now the fastest and most convenient way to spread ideas, express oneself and communicate with others under the information age [1]. There is great advantage in teaching practice with its effectiveness and universality.

Increasing Communication. Most of the practice activities are instructed by the teachers in their faculties to provide professional instructions to students. Due to the constraints of the time and space, during the practice, the students are scarcely able to communicate with instructors and their classmates, which greatly influences the effects of the practice activities. The lack of communication may result in less desired effects.

With the characters of communicating anytime and anywhere, micro blog can break the geographical limitations with free and effective communication between instructors and students. It can be used on both computers and phones, which is very convenient. The widely application of micro blog in teaching practice can make the normal students discuss problems with instructors at anytime and anywhere, and communicate with other students to share their feelings and perceptions in practice by posting their practice on the platform. Meanwhile, instructors can master the practice of students at anytime, anywhere. When students encounter problems, the instructor can discover that and take appropriate measures to help them, which can both enhance the communication and the quality of practice.

Improving the Ways of Management. The organization of most of the normal institutions of the practice of activities is according to the locations, practice environment and the ways of practices [2]. Students are scattered to different educational bases for practice. Some instructors are required to manage all internship students in one education base. Some may have to manage more bases, which may result in some problems, such as the ineffective management and instruction. The solution is the integration of the management from the instructors and the self management from the students to acquire a good result. When applying micro blog platform, students can publish their practice on the platform and record their practice which is a kind of effective self management. In this way, the students can improve their practice and help each other with micro blog, which may achieve better educational effect. The instructor can also keep a watchful eye on the students' practice and offer instruction and advice to better manage the students.

Improving the Accuracy of Evaluationt. Due to the shortage of instructors, they cannot track the students in the whole course of students' practice. Therefore, the students' grades are mostly appraised by teachers in the internship schools. Instructors of normal colleges and universities combine these achievements to give the final achievements of practice activities. This evaluation method is more casual and without too much basis, which cannot guarantee the validity of the evaluation. The application of micro blog can effectively improve the evaluation. With micro blog, the instructors can 
clearly master and evaluate the students' practice so as to give students an accurate evaluation of their practice. With micro blog, the instructor can effectively assess the students with the reference of micro blog. Meanwhile, it can also provide a wealth of experience for the future teachers and students when they carry out practice activities.

\section{Effective Ways in Applying Micro Blog in Normal School Students' Teaching Practice}

Recording Teaching Situation and Familiarizing Job Duties and Environment. In general, the normal students do not have a detailed understanding of the basic situation of the practice school, and do not have a general idea of the practice work, but they can understand that with micro blog. Before practice, the students can find some information about the culture of the school, its development, rules and regulations, theory of the school management and the work procedures from the official micro blog of the school and the teachers and students. During the first stage of practice, they can record educational situation, teaching links, mechanisms and information devices with micro blog. In this way, they make themselves familiar with the work content and share resources with the practical members to have more extensive and comprehensive understanding of their practice.

For example, in the practice mobilization, the micro blogs of the previous practice students can be shown to the future practice students to make them have a general idea of their practice so that they can prepare their practice and participate it in their best condition.

Building a Learning System and Enhancing the Communication Scope between Teachers and Students. Practice activities are generally carried out in groups. The practice sites and the contents are all different for each group. Even if they are in the same practice place, the subjects, objects, contents may vary greatly. In order to increase experience and improve their practice ability, the micro blog can be used to construct a common learning system to increase the communication between teachers and students. With micro blog, the internship students can release their practice and their feelings at anytime which may provide reference for other practice members.

In micro blog, the practice members can also strengthen communication, supervise and encourage each other to enhance their ability in practice activities. Instructors can conveniently master the students practice, supervise and regulate their practice to ensure the quality of their teaching practice. For example, the internship group leader and the class secretary can establish the micro blog forum. In this way, they can understand the practice situation both of the group members and other classmates, can also participate in the forum to increase their practice knowledge and experience.

Recording Teaching Log to Reflect and Improve Oneself. Teachers may inevitably encounter some problems in their work, so it is necessary to reflex what one has encountered in the teaching process. For the practice teaching of normal students, it is not enough to just have the experience of class listening, preparing and teaching. They must conclude their practice and reflex from their conclusion. Only in this way could they make repaid progress [3].

Teachers can use micro blog to write their teaching log including the students' classroom teaching and their feedback to reflex and conclude their teaching, which can make them easily find the causes of success and failure. Meanwhile, it is useful not only to their own development, but also profit to the communication with colleagues effectively and share of their experience and provision of efficient reference for their instruction of the future practice teaching. With micro blog, students can record their practice, which not only has a good preservation of their own practice experience, but also sums up their experience to have effective reflection and perfection and to lay a good foundation for their future learning, work and life. For example, during practice, instructors can require each student to record their practice log with micro blog, and display their micro blog after the practice so that students can learn from and exchange experience between each other. 


\section{Conclusions}

Micro blog is an indispensable communication platform in modern life. It can realize fast and convenient communication at anytime and anywhere. In teaching practice, the effective application of micro blog can bring great advantages. It can break the geographical limitations, share knowledge and exchange experience and feelings. The students can broaden their views, expand knowledge and sum up experience so as to enhance their practice ability. Teachers can facilitate the effective management and instructions to students and comment the practice results. Meanwhile, instructors should know that micro blog is only an auxiliary means of teaching practice. Teaching practical relies on professional knowledge and skills. So the application of micro blog in teaching practice needs rational eyesight to better teaching practice activities.

\section{Acknowledgements}

This work is supported by the "13th five" planned subject of the Jiangxi Province Educational Science(No.16YB146), Teaching Reform Project of Jiangxi Province Department of Education (No.JXJG-14-17-12), Humanities and social science research project in Jiangxi(No.JC161014, No.SZZX16060), Soft Science Research of Jiangxi Province(No.20161BBA10034), National Science Foundation of Jiangxi Province (No.20151BAB207013), Research Foundation of health department of Jiangxi Province China(No.20175561), Science Foundation of Jiangxi Provincial Department of Education(No.GJJ14739), Teaching Reform Project of Jiujiang University (No.XJJGYB-15-13,No.XJJGYB-16-14) ,Science Foundation of Jiujiang University (No.2016KJ001,No.2016KJ003).

\section{References}

[1] Li Xiaofei, Kang Ning \& Meng Jie. The Exploration of the Application of Micro Blog in Normal Students' Practice Teaching[J]. China Information Technology Education, 2014, 05: 124-126.

[2] Wu Liyuan \& Liang Qianqian. On the Application of Micro Blog in The Practice Teaching of Normal School Students [J]. Software Guide (Educational Technology), 2014, 09: 87-88.

[3] Feng Xiaoyan \& Xu Zhimin. The Application of micro blog in Teaching - The Reading Notes on Micro Blog [J]. Computer Education in Primary and Secondary Schools, 2015, 12: 21-23. 